\title{
Structural Characterization of Unsaturated Glycerophospholipids by Multiple-Stage Linear Ion-Trap Mass Spectrometry with Electrospray Ionization
}

\author{
Fong-Fu Hsu and John Turk \\ Mass Spectrometry Resource, Division of Endocrinology, Diabetes, Metabolism, and Lipid Research, \\ Department of Internal Medicine, Washington University School of Medicine, St. Louis, Missouri, USA
}

\begin{abstract}
Structural@lucidation@f@lycerophospholipids@GPLs),@ncluding@he@olar@head@roup, @he position@f@ouble-bond(s)@long@he@atty@cyl@ubstituents,@ndథhe@ositions@f@cyl@roups on@the@glycerol@backbone, Cusing@multiple-stage@liner@ion-trap@(LIT)@mass@spectrometric

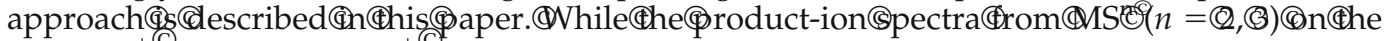

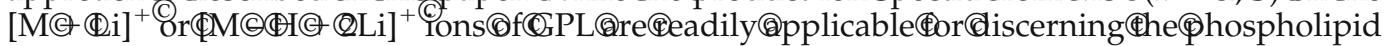
classes@ndథor@dentifying@nd(locating@heđatty@cid@ubstituents@n@he@lycerol@ackbone, the@structural@information@from@further@dissociation@of@the@dilithiated@fatty@acid@cations

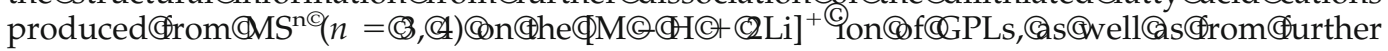

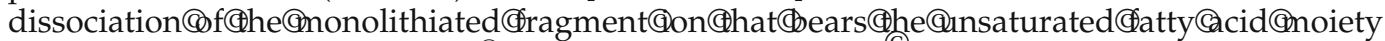

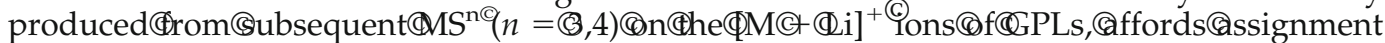
of@he@osition@f@ouble-bond(s)@long@he@atty@cyl@roups.@he@pplication@f(कhe@resent

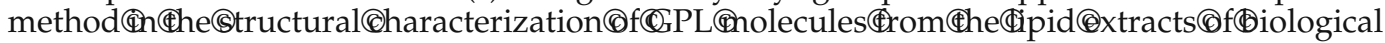
origin,@ncluding@nixtures@f(phosphatidylglycerol@nd@f@hosphatidylserine@without@prior chromatographic@eparation, (4s@lso@emonstrated.\$ince@ithiated@nolecular@pecies@f@PL@re

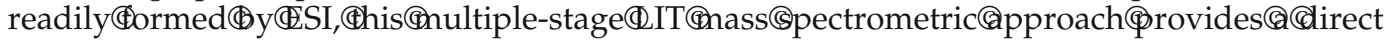
means@for@the@near-complete@structural@characterization@of@all@the@GPLs, @including@the molecules@n@he@ysophospholipid@nd@lasmalogen@ubclasses.@ (JCAm@Soc@Mass\&pectrom 2008,@9,@681-1691)@(2008@American@society@or@Mass@spectrometry
\end{abstract}

$\mathrm{E}$ lectrosprayđionization@(ESI)@with@tandem@mass spectrometry@technique@so@far@has@been@very successful@in@the@structural@characterization@of glycerophospholipids, $\odot$ including $($ assignment $\odot$ of@the head@roup, @he@atty@acid@ubstituents@nd@heir@ocation@t@he@lycerol@ackbone, (but@ot@ncluding@lucidation@of@the@position@of@the@double@bonds@of@the unsaturated@fatty@acid@constituents@1, (22], Cleading@to incomplete@haracterization.(Several@tudies@sing@raditional@hemical@eactions@i@ombination@ith@andem mass@spectrometry@to@locate@the@double-bond@of@the unsaturated@atty@cid@ubstituents@lave@een@eported. For@xample,@oe@t@1.@escribed@he@etermination@f the@osition@f@ouble@onds@f@he@unsaturated@atty acids@n@everal@phospholipid@lasses,@f@which@he double@bonds@of@the@fatty@acid@substituents@were converted@o@heir@icinal@ihydroxyl@hospholipids by@OsO $\mathrm{O}_{4}$ Cfollowed@by@tandem@mass@spectrometric

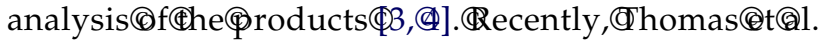
employed@zone@lectrospray@onization@and@zoneinduced@issociation@nass@pectrometry@o@lucidate

Address reprint requests to Dr. Fong-Fu Hsu, Box 8127, Washington University School of Medicine, 660 S. Euclid, St. Louis, MO 63110, USA. E-mail:@hsu@im.wustl.edu the@double-bond@position@in@unsaturated@fatty@acid constituents@n@@ariety@fđipids, $\mathbb{C}$ (n)luding@igcerophospholipids@and@sphingolipids@[5-7].๑These@latter approaches@re@imilar@o@he@arlier@ork@y@Harrison and@Murphy,@who@described $\mathbb{C}$ the $@$ characterization@of unsaturated@hosphatidylcholine@ipids@y@mass@pectrometric@nalysis@f@heđipid@zonides@onverted@rom phosphatidylcholine $₫ 8]$.

Among@he@forementioned@pproaches,@he@n-line ozone-induced@issociation@mass@pectrometry,@which permits@road@pplication@n@he@tructural@lucidation of@arious@ipids@in@mixture, Cappears@o@be@he@most promising \$5].बHowever, (4he@nethod@equires@@pecial set-up@that@is@not@readily@availableCto@all@he@mass spectrometers@to@enerate@toxic@and@orrosive@gas@of ozone@mitting@o@n@on-trap@nstrument@or@eaction. The@nethod@s@lso@ot@pplicable@or@ssignment@f $₫$ he fatty@cid@ubstituents@n®he@lycerol@ackbone.(Herein, we describe a multiple-stage mass spectrometric approach with a linear ion-trap instrument for structural characterization of glycerophospholipids, which were desorbed as the lithiated, dilithiated, or trilithiated adduct ions by ESI. This tandem mass spectrometric approach, leading to locating the unsaturated doublebond(s) of the fatty acid substituents in glycerophos- 
pholipids, is based on the findings described previously $[9,10]$. No effort was made to determine the stereochemistry and chirality of GPLs in this study.

\section{Experimental}

\section{Materials}

Standard 1-palmitoyl-2-oleoyl-3-sn-glycero-phosphoethanolamine (16:0/18:1- PE), 1-stearoyl-2-arachdonoyl-3-snglycero-phosphoethanolamine (18:0/20:4-PE), 1-ooctadec-1'enyl-2-oleoyl-sn-glycero-3-phosphoethanolamine ( $p 18: 1 / 18$ : 1-PE), 1-palmitoyl 2-linoleoy 3-sn-glycero-phosphatidic acid (16:0/18:2-PA), 1-palmitoyl 2-linoleoy 3-sn-glycero-phosphoserine (16:0/18:2-PS), 1-palmitoyl-2-oleoyl-3-sn-glycerophosphocholine (16:0/18:1-PC), 1-palmitoyl-2-docosahexaenoyl3-sn-glycerophosphocholine (16:0/22:6-PC), 1-oleoyl-2-lyso phosphatidylcholine (18:1/0-PC), phosphatidylglycerol mixture from Escherichia coli (E. Coli), and phosphatidylserine mixture from bovine brain were purchased from Avanti Polar Lipid Co. (Alabaster, AL); phosphatidylinositol extract from soybean was purchased from Sigma Chemical Co. (St. Louis, MO); 1-oleoyl-2-lyso phosphatidic acid (18:1/0-PA) was purchased from Serdary Research Laboratories (Ontario, Canada). All other reagents were of spectroscopic grade and were purchased from Fisher Chemical (St. Louis, $\mathrm{MO})$.

\section{Methods}

\section{Mass Spectrometry}

Linear ion-trap (LIT) mass spectrometry was conducted on a Finnigan LTQ (San Jose, CA) with Xcalibur operating system. GPL solution with $\mathrm{Li}^{+}$was prepared and continuously infused as described in the companion article [10]. The $\mathrm{MS}^{\mathrm{n}}$ experiments were carried out with an optimized relative collision energy ranging from $16 \%$ to $30 \%$ and with an activation $q$ value at 0.25 , and the activation time at 30 to $100 \mathrm{~ms}$ to leave a minimal residual abundance of precursor ion (around 20\%).

\section{Results and Discussion}

Upon being subjected to ESI in the presence of $\mathrm{Li}^{+}$, glycerophospholipids formed various lithiated molecular species that contained one to three lithium atoms (i.e., $\left.[\mathrm{M}+\mathrm{Li}]^{+}, \mathrm{M}-\mathrm{H}+2 \mathrm{Li}\right]^{+}$and $\left.\mathrm{M}-2 \mathrm{H}+3 \mathrm{Li}\right]^{+}$ ions), dependent on the phospholipid class, the number of the fatty acyl group attached to the molecule, and the concentration of $\mathrm{Li}^{+}$[11]. The fragmentation processes seen for the $[\mathrm{M}+\mathrm{Li}]^{+},[\mathrm{M}-\mathrm{H}+2 \mathrm{Li}]^{+}$or the $[\mathrm{M}-2 \mathrm{H}+$ $3 \mathrm{Li}]^{+}$ions of glycerophospholipids are similar, regardless of the phospholipid classes, following collision activated dissociation (CAD) in an ion-trap. The fragmentation pathways leading to locate the double-bond(s) of the unsaturated fatty acid are summarized in Scheme $\mathbf{1 .}$

\section{Characterization of Phosphatidylethanolamines}

Similar to the product-ion spectrum previously obtained with a tandem quadrupole instrument, the $[\mathrm{M}-\mathrm{H}+2 \mathrm{Li}]^{+}$ ion of 18:0/20:4-PE at $m / z 780$ (Figure 1a) contains the ions at $m / z 657$ and 651, representing a dilithiated and monolithiated diacylglycerol ions, respectively [11]. The spectrum also contains the ions at $m / z 496$ and 476 (Figure 1a, inset), arising from losses of 18:0- and 20:4-fatty acids substituents, respectively. The former ion is more abundant than the latter, indicating that the 18:0- and the 20:4-fatty acid substituents are located at $s n-1$ and $s n-2$, respectively $[2,11-13]$. Further dissociation of the ion at $m / z 657(780 \rightarrow 657$, Figure $1 b)$ gives rise to ions at $m / z 391$ and 367, arising from losses of the 18:0-fatty acid substituent as a ketene and as a lithium salt, respectively; the analogous losses of the 20:4-fatty acid residue results in the ions of $m / z 371$ and 347 . The ion at $m / z 371$ is more abundant than the ion at $\mathrm{m} / \mathrm{z} 391$, consistent with the notion that the $\alpha$-hydrogen of the fatty acid at $s n-2$ is more labile than that at $s n-1$, resulting in a more facile loss of a ketene residue at $s n-2[12,13]$. The ion at $m / z 367\left(657-\mathrm{C}_{17} \mathrm{H}_{35} \mathrm{CO}_{2} \mathrm{Li}\right)$ is more abundant than the ion at $m / z 347\left(657-\mathrm{C}_{19} \mathrm{H}_{31} \mathrm{CO}_{2} \mathrm{Li}\right)$; the ion at $m / z 317$ representing a dilithiated 20:4-fatty acid ion is also more abundant than the ion at $m / z 297$, representing a dilithiated 18:0-fatty acid (Figure 1b). The differential formation of the two ions in the pairs also provides information for assignment of the fatty acid substituents on the glycerol backbone. The location of double bonds (Scheme 1A) of the 20:4-fatty acid moiety is further deduced from the IT MS ${ }^{4}$ spectrum of the dilithiated fragment ion at $\mathrm{m} / \mathrm{z}$ 317 (780 $\rightarrow 657 \rightarrow 317$, Figure 1c), which contains two ion series at $m / z 219,179,139$ and at $m / z 167127$, and is identical to that from $\Delta^{5,8,11,14} 20: 4$ standard (in reference [10], Figure 4a), indicating that the compound is indeed an 18:0/ $\Delta^{5,8,11,14} 20: 4-\mathrm{PE}$.

By contrast, the LIT MS ${ }^{2}$ spectrum of the $[\mathrm{M}+\mathrm{Li}]^{+}$ ion of $18: 0 / \Delta^{5,8,11,14} 20: 4-\mathrm{PE}$ at $m / z 774$ (Figure $1 \mathrm{~d}$ ) is dominated by the ion at $m / z 731$, which arises from loss of ethanolamine group (loss as $\left[\mathrm{HOCH}_{2} \mathrm{CH}_{2} \mathrm{NH}_{2}-\right.$ $\left.\mathrm{H}_{2} \mathrm{O}\right]$ ) and gives rise to major ions at $m / z 633$ and 627 by further losses of the phosphate and lithium phosphate residues, respectively (774 $\rightarrow 731$, Figure $1 \mathrm{e}$ ). The ions of $m / z 490$ and 470 seen in Figure 1d derive from losses of 18:0- and 20:4-fatty acid substituents, respectively; and the ions at $m / z 447$ and 427 (Figure $1 \mathrm{~d}$ and e) arise from further loss of ethanolamine group. Again, the former ion in each set is more abundant than the latter ion, consistent with the assignment of the fatty acid substituents at the glycerol backbone $[2,11]$.

The ion at $m / z 633$ is probably equivalent to a lithiated ion of [diacylglycerol $-\mathrm{H}_{2} \mathrm{O}$ ], which gives rise to $m / z 351$ and 331 (Figure 1f, $780 \rightarrow 633$ ) by elimination of the 18:0and 20:4-fatty acids as $\alpha, \beta$-unsaturated fatty acids [14]. The ion at $m / z 349$ from loss of 18:0-fatty acid is more abundant than the ion at $\mathrm{m} / \mathrm{z} 329$ from loss of 20:4-fatty acid, consistent with the observation of a higher abundance of the $m / z 347$ ion (loss of 20:4-FA as a ketene) than 
(A) Dilithiated adduct ions: PE, PI and PG (including plasmalogens)

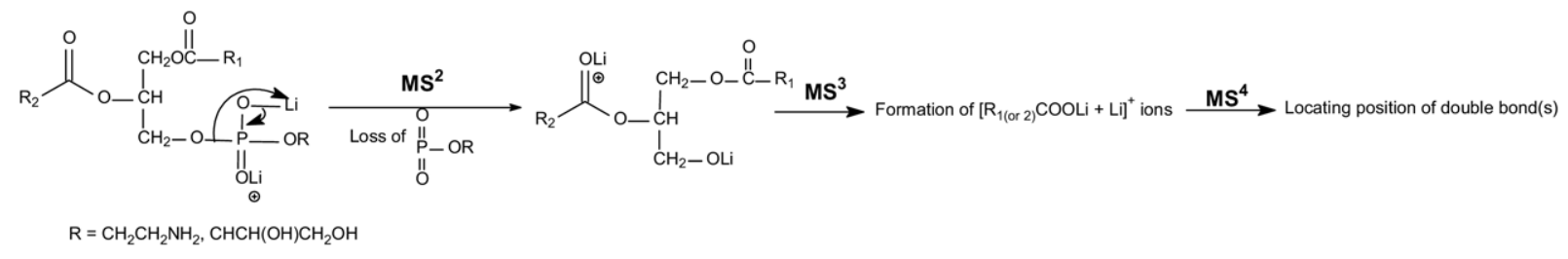

(B) Monolithiated adduct ions: applicable to all of the GPL classes that form [M + $\mathrm{Li}]^{+}$ions

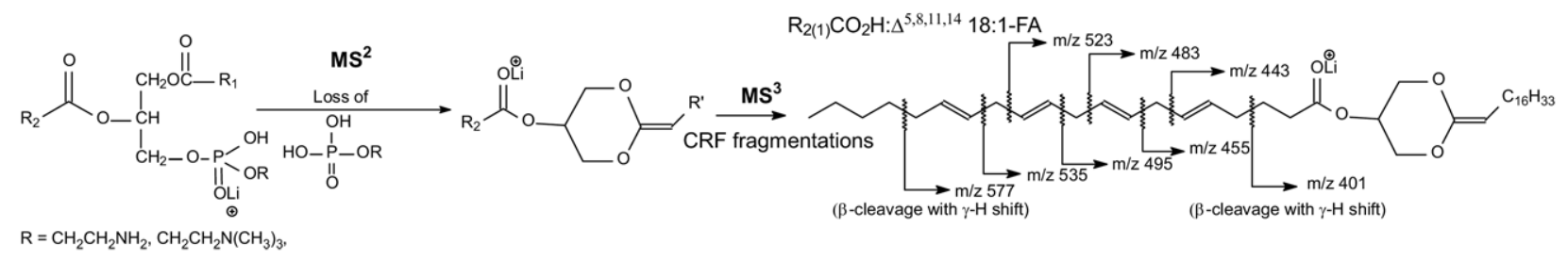

(C) Dilithiated and *trilithiated adduct ions: PS, PA and lyso PPL (*same fragment ions were produced by MS ${ }^{2}$ on trilithiated ions)

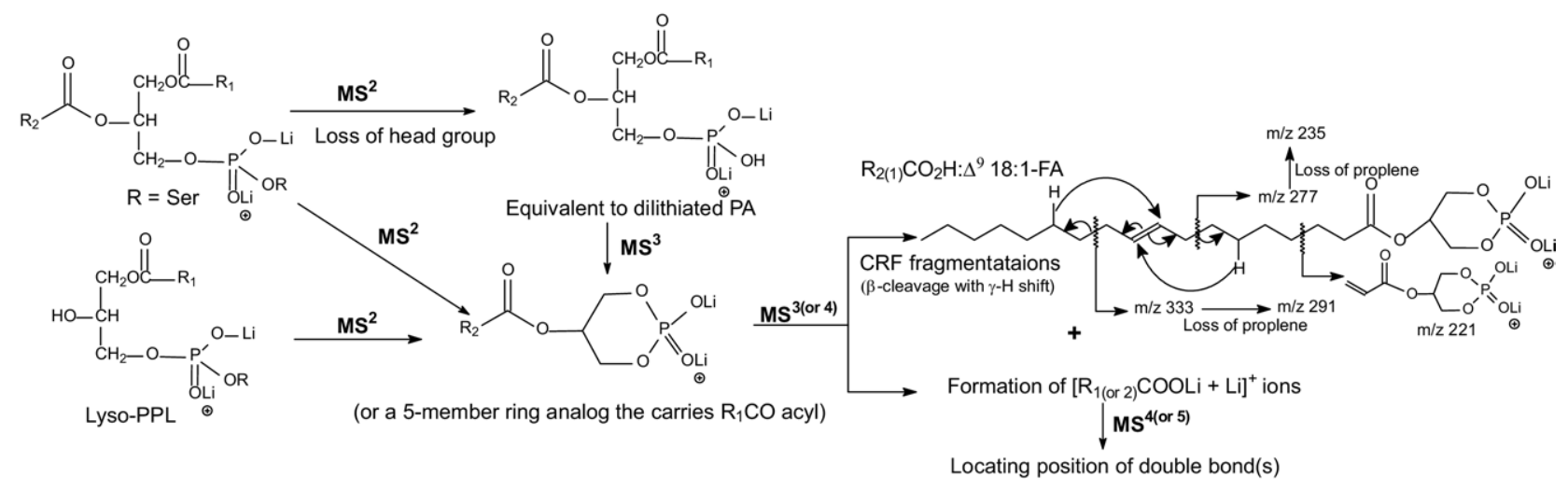

Scheme 1

$m / z 367$ ion (loss of 18:0-FA as a ketene). The differential formation of the above ion pairs along with the presence of the monolithiated ion pairs of 20:4- and 18:0-fatty acid at $m / z 311$ and 291 affords identification of the fatty acid substituents and their location on the glycerol backbone.

The position of double-bond(s) of the 20:4-fatty acid moiety is unveiled by the observation of two sets of ion series at $m / z 535,495,455$, and at $m / z 523,483$, and 443, along with $m / z 577$ (Figure 1f). These ions are analogous to the ions at $m / z 219,179,139,207,167,127$, and 261 seen in Figure 1c, and are 316 Da heavier. The results are consistent with notion that the ion at $m / z 633$ is a lithiated [diacylglycerol $-\mathrm{H}_{2} \mathrm{O}$ ] ion, which is $316 \mathrm{Da}$ heavier than the dilithiated 20:4-fatty acid ion at $\mathrm{m} / \mathrm{z}$ 317 . The results are in accord with the previously proposed fragmentation processes that cleave the allylic or vinyl bond with rearrangement of allylic hydrogen, as well as the CRF mechanism that undergoes McLafferty rearrangement (Scheme 1B) [10]. By contrast, the IT MS ${ }^{4}$ spectrum of the monolithiated ion of 20:4-fatty acid at $\mathrm{m} / \mathrm{z}$ $311(774 \rightarrow 633 \rightarrow 311$ ) (data not shown) does not contain the structural information for locating the position of double-bond(s), consistent with the results previously observed [10].
Similarly, the IT $\mathrm{MS}^{2}$ spectrum of the $[\mathrm{M}-\mathrm{H}+2 \mathrm{Li}]^{+}$ ion of 16:0/18:1-PE at $m / z 730$ (supplementary material, Figure s1a, which can be found in the electronic version of this article) contains the ions at $m / z 601$ and 607, representing a mono- and dilithiated diacylglycerol, respectively. The $m / z 474$ ion $(730-16: 0-F A)$ is more abundant than the $m / z 448$ ion (730 - 18:1-FA) (supplementary material, Figure s1a, inset), reflecting that the 16:0- and 18:1-fatty acids are located at $s n-1$ and $s n-2$, respectively. This structural assignment is consistent with the observation of the ion at $\mathrm{m} / \mathrm{z} 345$ (loss of 16:0-fatty acid lithium salt) is more abundant than the ion at $\mathrm{m} / \mathrm{z} 319$ (loss of 18:1-fatty acid lithium salt) in the $\mathrm{MS}^{3}$ spectrum of the ion at $m / z 607(730 \rightarrow 607$, supplementary material, Figure $\mathrm{s} 1 \mathrm{~b})$; while the ions at $m / z 295$ representing a dilithiated ions of 18:1-fatty acid is also more abundant than the ion at $m / z 269$, representing a dilithiated 16:0-fatty acid. The MS ${ }^{4}$ spectrum of the ion at $m / z 295(730 \rightarrow 607 \rightarrow 295$, supplementary material, Figure s1c) is identical to that arising from the $[\mathrm{M}-\mathrm{H}+2 \mathrm{Li}]^{+}$ion of $\Delta^{9} 18: 1$-fatty acid standard (see [10], Figure 1a), leading to assignment of the $16: 0 / \Delta^{9} 18: 1-P E$ structure. Again, the structural as- 

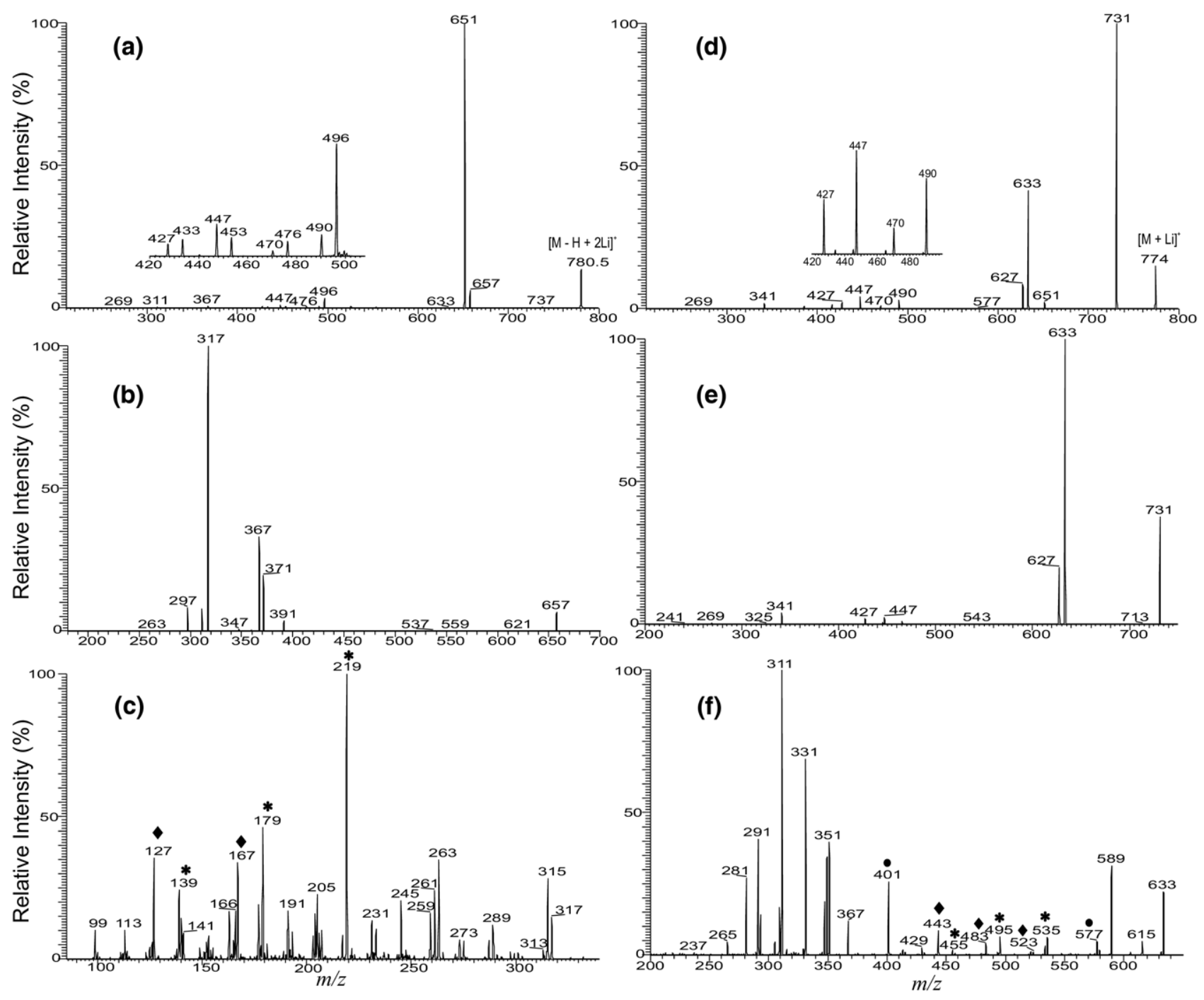

Figure 1. The LIT MS ${ }^{2}$ spectrum of the $[\mathrm{M}-\mathrm{H}+2 \mathrm{Li}]^{+}$ion of 18:0/20:4-PE at $m / z 780(\mathbf{a})$, the $\mathrm{MS}^{3}$ spectrum of the ion at $\mathrm{m} / \mathrm{z} 657(780 \rightarrow 657)(\mathbf{b})$, and the MS ${ }^{4}$ spectrum of the ion at $\mathrm{m} / \mathrm{z} 317(780 \rightarrow$ $657 \rightarrow 317)(\mathbf{c})$, the LIT MS ${ }^{2}$ spectrum of the $[\mathrm{M}+\mathrm{Li}]^{+}$ion of 18:0/20:4-PE at $m / z 774(\mathbf{d})$, the $\mathrm{MS}^{3}$ spectrum of the ion at $m / z 731(774 \rightarrow 731)(\mathbf{e})$, and the $\mathrm{MS}^{4}$ spectrum of the ion at $m / z 633(774 \rightarrow 731 \rightarrow$ 633) are also shown. The ions labeled with "filled diamond" (vinyl cleavage) and "asterisk" (allylic cleavage) are feature ions that identify the position of the double bonds of the 20:4-fatty acid moiety.

signment can also be achieved by the $\mathrm{MS}^{\mathrm{n}}(n=2,3)$ spectra from the $[\mathrm{M}+\mathrm{Li}]^{+}$ion of $m / z 724$, which gives rise to the prominent ion at $m / z 681(724 \rightarrow 681$, data not shown), which further dissociates to $m / z 583$, equivalent to a lithiated ion of [diacylglycerol $-\mathrm{H}_{2} \mathrm{O}$ ]. The $\mathrm{MS}^{4}$ spectrum of the ion at $\mathrm{m} / \mathrm{z} 583(724 \rightarrow 681 \rightarrow 583$, supplementary material, Figure s1d) comprises the ions at $m / z 485,429$, and 387, which are analogous to the ions at $m / z$ 197, 141, and 99 seen in Figure 2c, and are $288 \mathrm{Da}$ heavier. The results are consistent with the fact that the ion at $m / z 583$ is $288 \mathrm{Da}$ heavier than the $[\mathrm{M}-\mathrm{H}+2 \mathrm{Li}]^{+}$ ion of $\Delta^{9} 18: 1$-fatty acid at $m / z 295$. The IT MS ${ }^{2}$ spectrum of the $[\mathrm{M}-\mathrm{H}+2 \mathrm{Li}]^{+}$ion of $p 18: 1 / 18: 1-\mathrm{PE}$ at $\mathrm{m} / \mathrm{z} 740$ (supplementary material, Figure s1e) contains ions at $\mathrm{m} / \mathrm{z} 617$ (dilithiated diacylglycerol) and 611 (monolithi- ated diacylglycerol), along with $\mathrm{m} / \mathrm{z} 697$ arising from loss of ethanolamine (loss as [ethanolamine $-\mathrm{H}_{2} \mathrm{O}$ ]), and the ions reflecting loss of the fatty acid substituents are not present. This is consistent with the fact that the 1-Ooctadec-1'-enyl residue does not possess $\alpha$-hydrogen that is required for elimination of the adjacent fatty acid substituent [15]. Further dissociation of the ion at $\mathrm{m} / \mathrm{z}$ 617 (740 $\rightarrow$ 617, supplementary material, Figure s1f) gives rise to ions at $m / z 353$ and 329, arising from loss of the 18:1-fatty acid as a ketene and as a lithium salt, respectively, The spectrum also contains the dilithiated ion of 18:1-fatty acid at $\mathrm{m} / \mathrm{z} 295$, which yields a $\mathrm{MS}^{4}$ spectrum $(740 \rightarrow 617 \rightarrow 295$, data not shown) identical to Figure s1c, upon CAD. The results demonstrated that the compound is a $p 18: 1 / \Delta^{9} 18: 1-\mathrm{PE}$. 

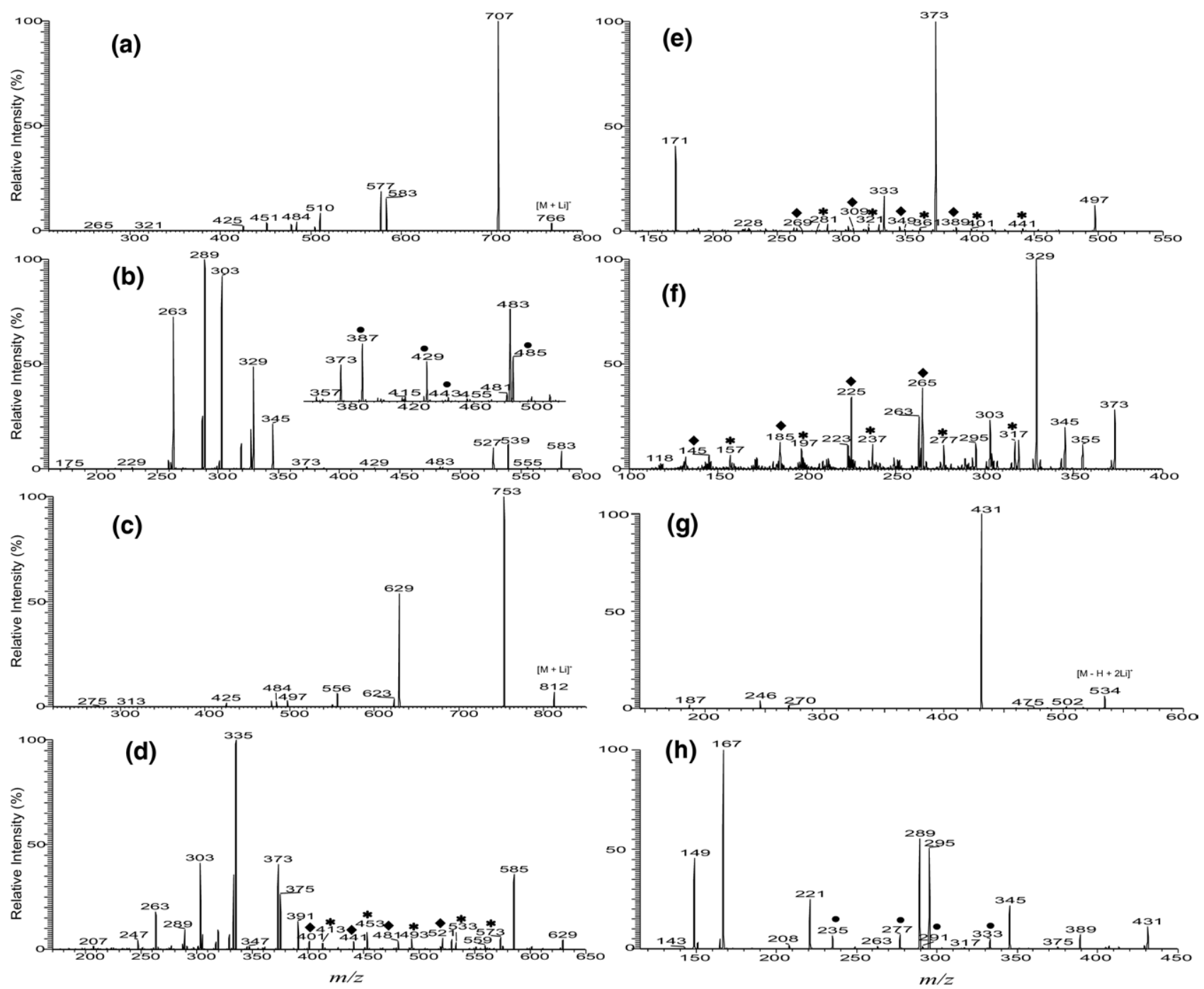

Figure 2. The LIT MS ${ }^{2}$ spectrum of the $[\mathrm{M}+\mathrm{Li}]+$ ion of $16: 0 / 18: 1-\mathrm{PC}$ at $m / z 766(\mathbf{a})$ and the $\mathrm{MS}^{3}$ spectrum of the ion at $m / z 583(766 \rightarrow 583)(\mathbf{b})$. Panel $(\mathbf{c})$ shows the $[\mathrm{M}+\mathrm{Li}]^{+}$ion of 16:0/22:6-PC at $\mathrm{m} / \mathrm{z}$ 812. The feature ions [labeled with "filled diamond" (vinyl cleavage); "asterisk" (allylic cleavage)] seen in the MS ${ }^{3}$ spectra of the ions at $m / z 629(812 \rightarrow 629)(\mathbf{d})$, at $m / z 497(812 \rightarrow 497)(\mathbf{e})$ and its MS spectrum of $\mathrm{m} / \mathrm{z} 373(812 \rightarrow 497 \rightarrow 373)$ (f) lead to assignment of the homoconjugated fatty acid moiety of $\Delta^{4,7,10,13,16,19} 22: 6$ of the molecule. The LIT MS ${ }^{2}$ spectrum of the $[\mathrm{M}-\mathrm{H}+2 \mathrm{Li}]^{+}$ion of 18:1/0-PC at $\mathrm{m} / \mathrm{z} 534(\mathrm{~g})$ and the $\mathrm{MS}^{3}$ spectrum of the ion at $\mathrm{m} / \mathrm{z} 431(534 \rightarrow 431)(\mathbf{h})$ are also shown. Ions labeled with "filled circle" in panel (h) signify that the molecule is a $\Delta^{9} 18: 1 / 0-\mathrm{PC}$.

\section{Characterization of Phosphatidylcholines}

Phosphatidylcholine forms mainly monolithiated adduct ions, when subjected to ESI in the presence of $\mathrm{Li}^{+}$ [13]. As seen in Figure 2a, the LIT MS ${ }^{2}$ spectrum of the $\left[\mathrm{M}+\mathrm{Li}^{+}\right.$ion of 16:0/18:1-PC at $\mathrm{m} / \mathrm{z} 766$ is dominated by the ion at $\mathrm{m} / \mathrm{z} 707$ from loss of the $\mathrm{N}\left(\mathrm{CH}_{3}\right)_{3}$ group, along with the ions at $\mathrm{m} / \mathrm{z} 583$ and 577, arising from losses of the phosphocholine polar group as an acid and as a lithium salt respectively. Again, the assignment of the 16:0-fatty acid at $s n-1$ and the 18:1-fatty acid at $s n-2$, is based on the presence of a higher abundance of the ion at $\mathrm{m} / \mathrm{z} 510$ from loss of 16:0-fatty acid substituent than the ion at $\mathrm{m} / \mathrm{z} 484$ corresponding to the loss of the 18:1-fatty acid substituent [13]. The ion at $\mathrm{m} / \mathrm{z} 583$ is equivalent to the same ion arising from the $[\mathrm{M}+\mathrm{Li}]^{+}$ ion of 16:0/18:1-PE at $\mathrm{m} / \mathrm{z} 724$, which eliminates the phosphoethanolamine head group (loss of a $141 \mathrm{Da}$ residue) upon CAD. This is supported by the $\mathrm{MS}^{3}$ spectrum of the ion at $m / z 583(766 \rightarrow 583$, Figure $2 b)$, which is identical to that shown in Figure s1d. The results also demonstrated that the double-bond of the 18:1-fatty acid at $s n-2$ is located at C(9), consistent with the $16: 0 / \Delta^{9} 18: 1-P C$ structure.

Similarly, the $\mathrm{MS}^{2}$ spectrum of the $[\mathrm{M}+\mathrm{Li}]^{+}$ion of 16:0/22:6-PC at $m / z 812$ (Figure 2c) is dominated by the ion at $m / z 753\left(812-\mathrm{N}\left(\mathrm{CH}_{3}\right)_{3}\right)$, which gives rise to ions at $\mathrm{m} / \mathrm{z} 629$ and 623 by losses of ethylene phosphate and lithium ethylene phosphate residues, respectively 
$[2,13]$. The ion at $m / z 629$ is more abundant than the ion at $m / z 623$, consistent with the fact that the compound contains a polyunsaturated fatty acid moiety $[2,13]$. The position of double bonds of the 22:6-fatty acid moiety is unveiled by the product-ion spectrum of the ion at $\mathrm{m} / \mathrm{z}$ 629 originated from $\mathrm{MS}^{3}\left(812 \rightarrow 629\right.$, Figure $2 \mathrm{~d}$ ) or $\mathrm{MS}^{4}$ ( $812 \rightarrow 753 \rightarrow 629$, not shown), which contains two sets of ion series at $m / z 521,481,441$, and 401 , and at $m / z 573$, $533,493,453$, and 413 from the fragmentation pathways that involve the participation of the allylic hydrogens shown earlier [10]. These ions clearly located the double bonds at $C(4), C(7), C(10), C(13), C(16)$, and $C(19)$, while the ions at $\mathrm{m} / \mathrm{z} 335$ (lithiated 22:6-FA), 263 (lithiated 16:0-FA), 375 (loss of $\alpha, \beta$-unsaturated 16:1-FA), 303 (loss of $\alpha, \beta$-unsaturated 22:7), 391 (loss of 16:0-FA), 373 (loss of 16:0-ketene), 319 (loss of 22:6-FA), and 301 (loss of 22:6ketene) are analogous to those seen in Figure $1 \mathrm{f}$ and are readily applicable to identify the fatty acid substituents and to locate their position on the glycerol backbone.

The $\mathrm{MS}^{3}$ spectrum of the ion at $m / z 497(812 \rightarrow 497$, Figure 2e) contains two ion series at $m / z 389,349,309$, and 269 , and at $\mathrm{m} / \mathrm{z} 441,401,361,321$, and 281, which are $136 \mathrm{Da}$ higher than those seen for $\Delta^{4,7.10 .13 .16 .19} 22$ : 6-FA at $m / z 341$ [10], consistent with the notion that the ion at $\mathrm{m} / \mathrm{z} 497$, arising from the combined losses of the $\mathrm{N}\left(\mathrm{CH}_{3}\right)_{3}(59 \mathrm{Da})$ and 16:0-fatty acid (256 Da) is $136 \mathrm{Da}$ heavier than the ion at $m / z 341$. The MS ${ }^{4}$ spectrum of the ion at $m / z 373(812 \rightarrow 497 \rightarrow 373$, Figure $2 \mathrm{f})$ contains the ion series at $\mathrm{m} / \mathrm{z} 265,225,185$, and 145 and at $\mathrm{m} / \mathrm{z} 317$, $277,237,197$, and 157, which is 124 Da lighter than the analogous ions seen in Figure 2e, further supporting that the compound is indeed a $16: 0 / \Delta^{4,7.10 .13 .16 .19} 22: 6-$ PC. The results are also consistent with the notion that the ion at $\mathrm{m} / \mathrm{z} 373$ arises from loss of an ethylene phosphate (124 Da) residue.

By contrast, 2-lyso-PC formed mainly dilithiated adduct ions by ESI. As shown in Figure $2 \mathrm{~g}$, the LIT MS ${ }^{2}$ spectrum of the $[\mathrm{M}-\mathrm{H}+2 \mathrm{Li}]^{+}$ion of $18: 1 / 0-\mathrm{PC}$ at $\mathrm{m} / \mathrm{z} 534$ is dominated by the ion at $m / z 431$, which represents a dilithiated 1-acyl-2,3-cyclophosphate ion arising from loss of choline residue. This is further supported by the MS $^{3}$ spectrum of the ion at $m / z 431$ (534 $\rightarrow 431$, Figure $2 \mathrm{~h}$ ), which contains ions at $\mathrm{m} / \mathrm{z} 167$ and 149, arising from losses of the 18:1-fatty acid as a ketene and as an acid respectively. The ion at $\mathrm{m} / \mathrm{z} 345$ may arise from loss of $\mathrm{PO}_{3} \mathrm{Li}$, while ions at $\mathrm{m} / \mathrm{z} 289$ and 295 correspond to mono- and dilithiated cations of 18:1-fatty acid, respectively. The ions that recognize the position of doublebond were seen at $\mathrm{m} / \mathrm{z} 333$ and 277 arising from the CRF processes that undergo McLafferty rearrangement (Scheme 1C). These ions also yield ions at $m / z 291$ and 235 by elimination of a $\mathrm{CH}_{2}=\mathrm{CH}-\mathrm{CH}_{3}$ residue; while the ion at $m / z 221$ arises from cleavage of $C(3)-C(4)$ bond to yield a stable conjugated ion (Scheme 1C), analogous to the ion at $m / z 401$ seen in Figure 1f (also see Scheme 1B). The results indicate that the ion at $\mathrm{m} / \mathrm{z} 534$ is a $\Delta^{9} 18: 1 / 0-\mathrm{PC}$, consistent with the assignment deduced from $\mathrm{MS}^{4}$ spectrum of $m / z 295$ (534 $\rightarrow 431 \rightarrow 295$, data not shown), which is identical to that shown in Figure s1c.

\section{Characterization of Phosphatidic Acids}

Phosphatidic acids formed dilithiated and trilithiated ions, in the presence of $\mathrm{Li}^{+}$. Both the $\mathrm{MS}^{2}$ spectra from the $[\mathrm{M}-\mathrm{H}+2 \mathrm{Li}]^{+}$and $[\mathrm{M}-2 \mathrm{H}+3 \mathrm{Li}]^{+}$adduct ions are simple and are dominated by the ions arising from losses of the fatty acid substituents. As shown in Figure $3 \mathrm{a}$, the $\mathrm{MS}^{2}$ spectrum of the $[\mathrm{M}-\mathrm{H}+2 \mathrm{Li}]^{+}$ion of 16:0/18:2-PA at $\mathrm{m} / \mathrm{z} 685$ contains prominent ions at $\mathrm{m} / \mathrm{z}$ 429 and 405, arising from losses of the 16:0- and 18:2-fatty acid substituents, respectively. The former ion is more abundant than the latter, consistent with that the predominant regioisomer is consisted of a 16:0-fatty acid at $s n-1$ and a 18:2-fatty acid at $s n-2$. The ion at $\mathrm{m} / \mathrm{z}$ $429(685-256)$ is a dilithiated 1-acyl-2,3-cyclo-phosphate ion, analogous to the ion at $\mathrm{m} / \mathrm{z} 431$ (534 - choline) seen in Figure $2 \mathrm{~g}$ and gives rise to a $\mathrm{MS}^{3}$ spectrum $(685 \rightarrow$ 429 , Figure $3 b$ ) similar to that arising from $\mathrm{m} / \mathrm{z} 431$ (Figure $2 \mathrm{~h}$ ). However, the spectrum also contains the ion series at $\mathrm{m} / \mathrm{z} 373$ and 277 from $\beta$-cleavage with $\gamma$-hydrogen rearrangement and the ion series at $\mathrm{m} / \mathrm{z} 331$ and 319 arising from the fragmentation processes that involves allylic hydrogen ( $\alpha$-cleavage), along with the ions at $\mathrm{m} / \mathrm{z} 263$ and 235 from consecutive $\beta$-cleavages. These ions are $136 \mathrm{Da}$ heavier than the analogous ions at $m / z 237,141,195,183,127$, and 99 seen in the $\mathrm{MS}^{4}$ spectrum of the ion at $m / z 293(685 \rightarrow 429 \rightarrow 293$, Figure $3 c)$, which represents a dilithiated $\Delta^{9,12} 18: 2$-fatty acid ion. The results suggest that the ion at $\mathrm{m} / \mathrm{z} 685$ is a dilithiated 16:0/ $\Delta^{9,12} 18: 2-\mathrm{PA}$. The $\mathrm{MS}^{2}$ spectrum of the $[\mathrm{M}-2 \mathrm{H}+3 \mathrm{Li}]^{+}$ion of the same molecule at $\mathrm{m} / \mathrm{z} 691$ (Figure 3d) is also dominated by the ions at $\mathrm{m} / \mathrm{z} 429$ and 405. However, the abundances of these two ions reflecting losses of the 16:0- and 18:2-fatty acid substituents as lithium salts, respectively, are reversed (compared with Figure 3a), indicating that they may arise from different fragmentation pathways. The $\mathrm{MS}^{3}$ spectrum of the ion at $m / z 429(691 \rightarrow 429$, Figure 3e) is nearly identical to that shown in Figure $3 \mathbf{b}$, however, the ions at $m / z 411$ and 405 reflecting losses of $\mathrm{H}_{2} \mathrm{O}$ and $\mathrm{LiOH}$, respectively, are also seen. This difference in the $\mathrm{MS}^{3}$ spectra of $\mathrm{m} / \mathrm{z}$ 429 originated from the precursor ions that are varied by the number of lithium ion attached is consistent with the earlier finding that the $[\mathrm{M}-\mathrm{H}+2 \mathrm{Li}]^{+}$and the $[\mathrm{M}-$ $2 \mathrm{H}+3 \mathrm{Li}]^{+}$ions of $16: 0 / \Delta^{9,12} 18: 2-\mathrm{PA}$ may undergo different fragmentation pathways upon CAD. In Figure $3 a$, the ions at $m / z 429$ and 405 formed by losses of the 16:0- and 18:2-fatty acid substituents, respectively, may involve the participation of $\alpha$-hydrogen of the neighboring fatty acid, leading to more favorable loss of the 16:0-FA at sn-1; while these two ions seen in Figure 3d are formed from losses of the fatty acid as lithium salt, in which the lithium ion participating in the losses may reside at the phosphate group, which is in a closer vicinity to the $s n-2$ fatty acid moiety, leading to a more favorable loss of the fatty acid (as lithium salt) at sn-2. The $\mathrm{MS}^{3}$ spectrum of the $m / z 429$ ion $(691 \rightarrow 429$, Figure 3e) and the MS ${ }^{4}$ spectrum of the ion at $m / z 293(691 \rightarrow$ $429 \rightarrow 293$, data not shown) are nearly identical to that 


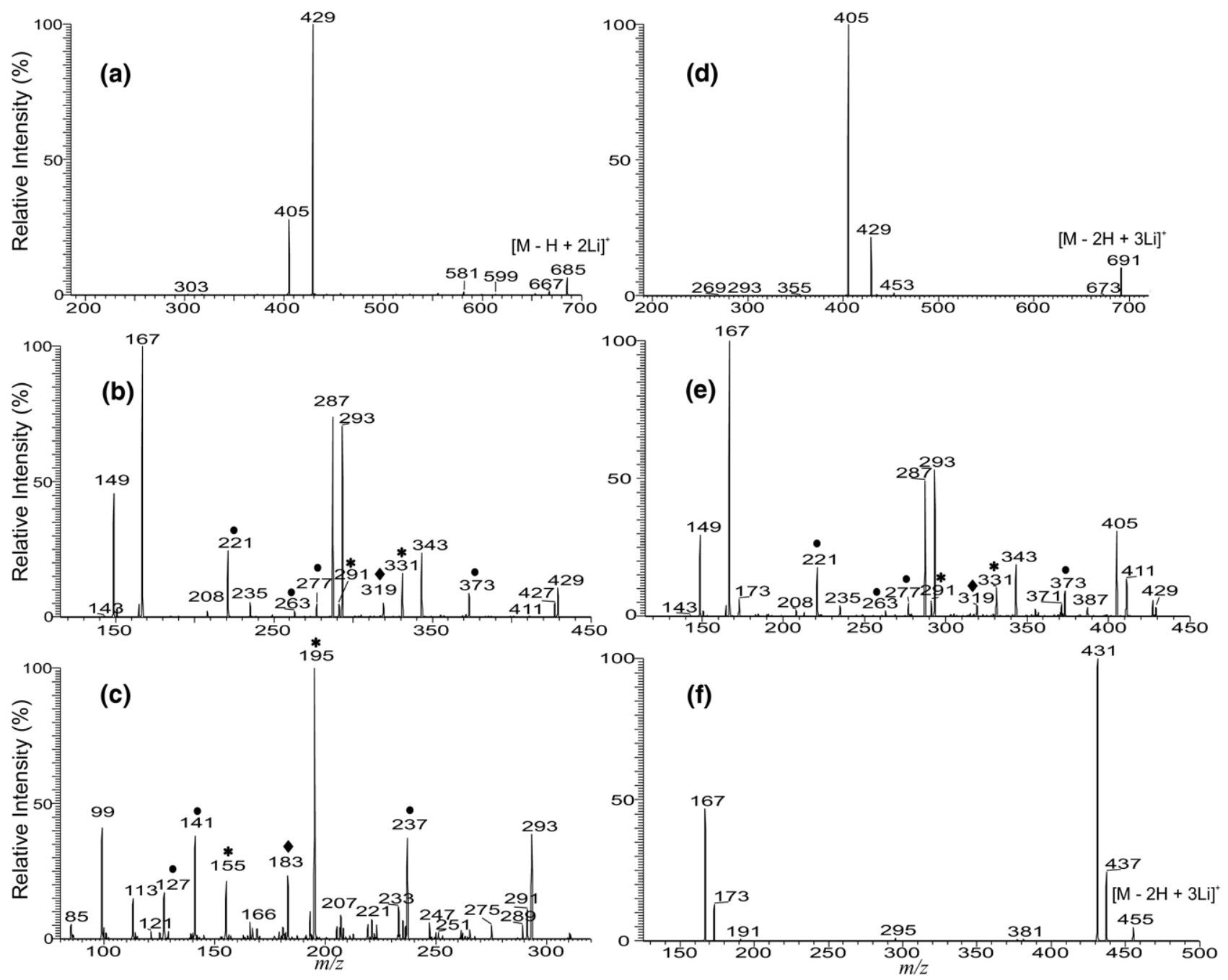

Figure 3. The LIT MS ${ }^{2}$ spectrum of the $[\mathrm{M}-\mathrm{H}+2 \mathrm{Li}]^{+}$ion of $16: 0 / 18: 2-\mathrm{PA}$ at $m / z 685(\mathbf{a})$, the $\mathrm{MS}^{3}$ spectrum of the ion at $\mathrm{m} / z 429(685 \rightarrow 429)(\mathbf{b})$, and the MS ${ }^{4}$ spectrum of the ion at $\mathrm{m} / \mathrm{z} 293(685 \rightarrow$ $429 \rightarrow 293)$. (c), The LIT MS ${ }^{2}$ spectrum of the $[\mathrm{M}-2 \mathrm{H}+3 \mathrm{Li}]^{+}$ion of 16:0/18:2-PA at $\mathrm{m} / \mathrm{z} 691(\mathbf{d})$, and the $\mathrm{MS}^{3}$ spectrum of the ion at $m / z 429(685 \rightarrow 429)(\mathbf{e})$, are similar to those shown in (a) and (b), respectively. The combined structural information demonstrated that the compound is a $16: 0 / \Delta^{9,12} 18$ : 2-PA. Panel (f) shows the $\mathrm{MS}^{2}$ spectrum of the $[\mathrm{M}-2 \mathrm{H}+3 \mathrm{Li}]^{+}$ion of 18:1/0-PA at $\mathrm{m} / z$ 455, which contains the ion at $m / z 431$ that yields an $\mathrm{MS}^{3}$ spectrum identical to Figure 4a. The ions labeled with "filled circle", "filled diamond" and "asterisk" [panel (b) and (e)] locate the double bonds on $\Delta^{9,12} 18: 2$.

shown in Figure $3 \mathrm{~b}$ and $\mathrm{c}$, respectively, confirming the assignment of the 16:0/ $\Delta^{9,12} 18: 2-\mathrm{PA}$ structure.

By contrast, Lyso-PA forms mainly $[\mathrm{M}-2 \mathrm{H}+3 \mathrm{Li}]^{+}$ ions, when subjected to ESI. Upon CAD, the $[\mathrm{M}-2 \mathrm{H}+3$ $\mathrm{Li}^{+}$ion at $m / z 455$ of 18:1/0-PA (Figure 3f) gives rise to prominent ions at $\mathrm{m} / \mathrm{z} 437$ and 431, corresponding to losses of $\mathrm{H}_{2} \mathrm{O}$ and $\mathrm{LiOH}$, respectively, along with the ions at $m / z 173$ and 167 corresponding to losses of the 18:1fatty acid substituent as an acid and as a lithium salt, respectively. Further fragmentation of the ion at $m / z 431$ $\left(455 \rightarrow 431\right.$, data not shown) yields a $\mathrm{MS}^{3}$ spectrum that is identical to that shown in Figure $2 \mathrm{~h}$, and the $\mathrm{MS}^{4}$ spectrum of the $m / z 295$ ion $(455 \rightarrow 431 \rightarrow 295$, data not shown) is also identical to that shown in Figure s1, consistent with the fact that the compound is a $\Delta^{9} 18: 1 / 0-\mathrm{PA}$.

\section{Characterization of Phosphatidylinositol from Soybean}

The major PI species from soybean was seen at $m / z$ 847, which represents a $[\mathrm{M}-\mathrm{H}+2 \mathrm{Li}]^{+}$ion of 16:0/18:2-PI. The LIT MS ${ }^{2}$ spectrum of the ion at $m / z 847$ (Figure 4a) contains major ions at $m / z 255$, representing a dilithiated inositol-1,2-cyclic phosphate cation [16], and at $m / z 605$ and 599, arising from losses of the inositol-1,2-cyclic phosphate as an acid and as a lithium salt, respectively. The ion at $m / z 429$ arising from consecutive losses of the inositol head group (loss as [inositol $-\mathrm{H}_{2} \mathrm{O}$ ]) and 16:0-fatty acid substituent is more abundant than the ion at $m / z 405$, arising from the analogous losses of the 18:2-fatty acid substituent, indicating the ion may rep- 


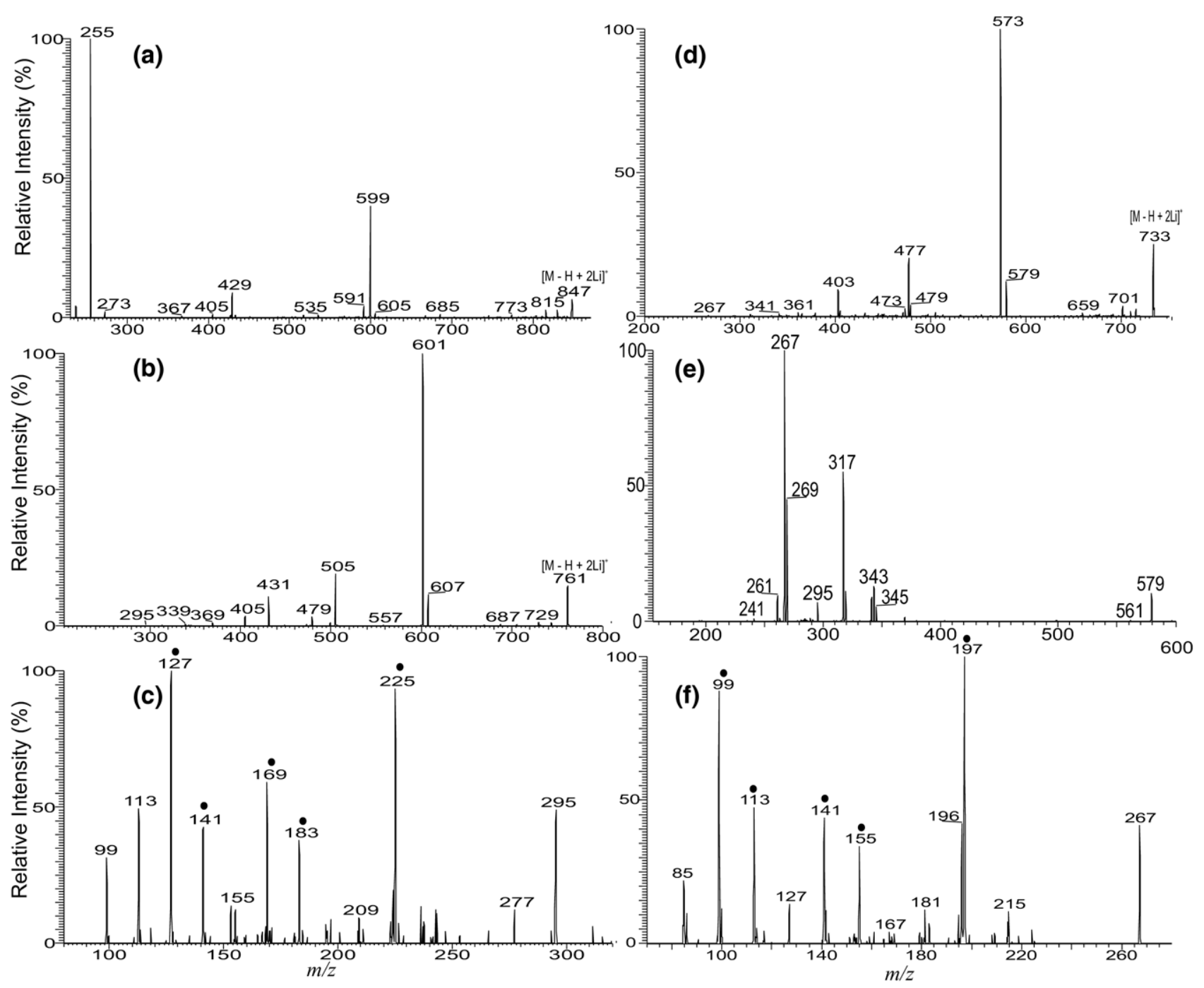

Figure 4. The LIT MS ${ }^{2}$ spectrum of the $[\mathrm{M}-\mathrm{H}+2 \mathrm{Li}]^{+}$ion of 16:0/18:2-PI at $\mathrm{m} / \mathrm{z} 847$ from lipid extract of soybean (a), and the $\mathrm{MS}^{2}$ spectrum of the $[\mathrm{M}-\mathrm{H}+2 \mathrm{Li}]^{+}$ion of $16: 0 / 18: 1-\mathrm{PG}$ at $\mathrm{m} / \mathrm{z} 761$ from PG extract of e. coli (b). Further dissociation of the ions at $\mathrm{m} / z 429(847 \rightarrow 429)$ and at $\mathrm{m} / z 293(847 \rightarrow$ $429 \rightarrow 293)$ lead to assignment of 16:0/ $\Delta^{9,12} 18: 2$-PI; while the MS ${ }^{3}$ spectrum of $m / z 295(761 \rightarrow 607 \rightarrow$ $295)$ (c) results in assignment of the $\Delta^{11} 18: 1$-fatty acid moiety in $16: 0 / \Delta^{11} 18: 1-P G$. The combined information from the $\mathrm{MS}^{2}$ spectrum of the $[\mathrm{M}-\mathrm{H}+2 \mathrm{Li}]^{+}$ion of 16:0/16:1-PG at $\mathrm{m} / \mathrm{z} 733$ from $E$. coli (d), its $\mathrm{MS}^{3}$ spectrum of $m / z 579(\mathbf{e})$, and its $\mathrm{MS}^{4}$ spectrum of the ion at $\mathrm{m} / \mathrm{z} 267(733 \rightarrow 579 \rightarrow 267)$

(f) results in assignment of 16:0/ $\Delta^{9} 16: 1-P G$.

resent mainly a 16:0/18:2-PI regioisomer. Further dissociation of the ion at $m / z 429$ yields an $\mathrm{MS}^{3}$ spectrum $((847 \rightarrow 429$, data not shown) identical to that shown in Figure $3 \mathrm{~b}$, consistent with the notion that the ion at $\mathrm{m} / \mathrm{z}$ 429 arises from losses of polar head group and 16:0-fatty acid moiety. The MS 4 spectrum of the ion at $\mathrm{m} / \mathrm{z} 293$ $(847 \rightarrow 429 \rightarrow 293)$ (data not shown), is also identical to that shown in Figure $3 c$, which is identical to that arising from $\Delta^{9,12} 18: 2$ fatty acid standard. The above results clearly demonstrated that the ion arises mainly from a $16: 0 / \Delta^{9,12} 18: 2$-PI regioisomer.

\section{Characterization of Phosphatidylglycerol from E. coli}

The major dilithiated molecular ions of phosphatidylglycerol from $E$. coli were seen at $m / z$ 733, 747, 759, 761,
775 , and 787 (data not shown). The structural characterization, including the location of double-bond of the unsaturated fatty acid constituents in the molecules is exemplified by the ions seen at $\mathrm{m} / \mathrm{z} 761$ and 733 . As shown in Figure $4 b$, the LIT MS ${ }^{2}$ spectrum of the $[\mathrm{M}-\mathrm{H}+$ $2 \mathrm{Li}]^{+}$ions at $\mathrm{m} / \mathrm{z} 761$ contains the ions at $\mathrm{m} / \mathrm{z} 607$ and 601 , representing a dilithiated and monolithiated anhydr diacylglycerol cations, respectively, similar to those seen in the $\mathrm{MS}^{2}$ spectrum of 16:0/18:1-PE at $\mathrm{m} / \mathrm{z}$ 730 (Figure s1a). The results are consistent with the fact that the ions arise from cleavage of the $\mathrm{O}-\mathrm{PO}_{3}$ bond to eliminate the polar head group (Scheme 1A). This fragmentation process is common to all the $[\mathrm{M}-\mathrm{H}+$ $2 \mathrm{Li}]^{+}$ions of glycerophospholipids. The spectrum (Figure 6a) also contains the ions at $m / z 505$ and 479 , arising from losses of the 16:0- and 18:1-fatty acid substituents, 

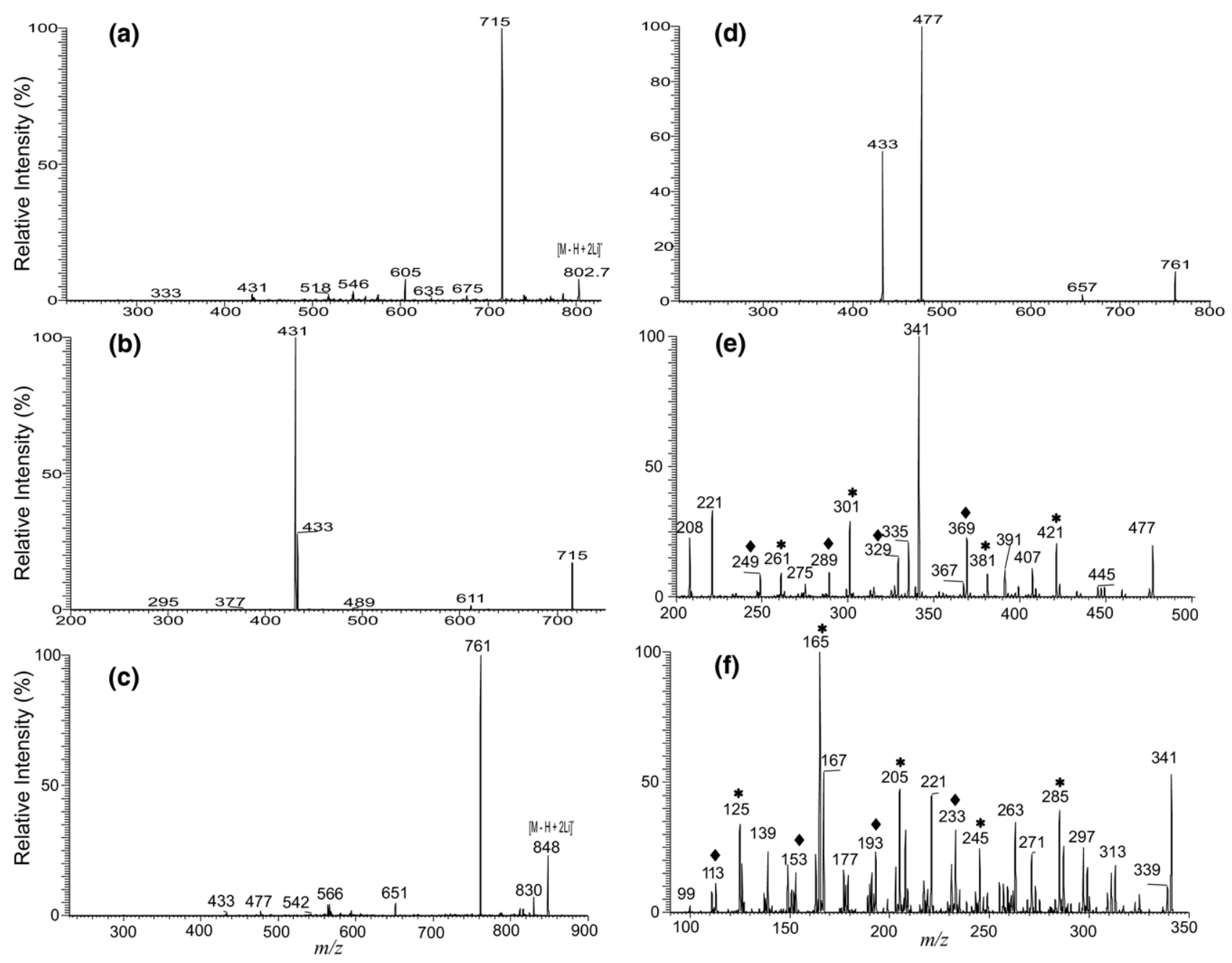

Figure 5. The LIT MS ${ }^{2}$ spectrum of the $[\mathrm{M}-\mathrm{H}+2 \mathrm{Li}]^{+}$ion of 18:0/18:1-PS from lipid extract of bovine brain at $m / z 802(\mathbf{a})$, its $\mathrm{MS}^{3}$ spectrum of $m / z 715(802 \rightarrow 715)(\mathbf{b})$; and the LIT MS ${ }^{2}$ spectrum of the $[\mathrm{M}-\mathrm{H}+2 \mathrm{Li}]^{+}$ion of 18:0/22:6-PS at $m / z 848(\mathbf{c})$, its $\mathrm{MS}^{3}$ spectrum of $m / z 761(848 \rightarrow 761)(\mathbf{d})$, $\mathrm{MS}^{4}$ of $m / z 477(848 \rightarrow 761 \rightarrow 477)(\mathbf{e})$, and $\mathrm{MS}^{5}$ of the ion at $m / z 341(848 \rightarrow 761 \rightarrow 477 \rightarrow 341)(\mathbf{f})$. The ions leading to locating the double bonds of the fatty acid substituents in $18: 0 / \Delta^{4,7,10,13,16,19} 22: 6$-PS are labeled with "filled circle", "filled diamond", and "asterisk" [Panel (e) and (f)].

respectively, along with the ions at $m / z 431$ and 405, from further loss of the glycerol head group (loss as [glycerol $-\mathrm{H}_{2} \mathrm{O}$ ]). The former ions in each pair are more abundant than those in the latter pair, indicating that the ion at $m / z 761$ is mainly a $16: 0 / 18: 1-P G$ regioisomer. The consecutive dissociation of the ion at $\mathrm{m} / \mathrm{z} 607$ also gives rise to a $\mathrm{MS}^{3}$ spectrum $(761 \rightarrow$ 607, data not shown) identical to that shown in Figure $\mathrm{s} 1 \mathrm{~b}$, suggesting that the 16:0- and 18:1-fatty acids are located at $s n-1$ and $s n-2$, respectively. The LIT MS ${ }^{4}$ spectrum of $m / z 295(761 \rightarrow 607 \rightarrow 295$, Figure $4 c)$ is featured by the prominent ion-pair of $\mathrm{m} / \mathrm{z} 225 / 169$, along with the ions at $\mathrm{m} / \mathrm{z} 183,141$, and 127 and is identical to that shown in Figure $2 d$ in the companion article [10], demonstrating that the double-bond of the 18:1-fatty acid substituent is located at $C(11)$. The above results give assignment of the $16: 0 / \Delta^{11} 18: 1-\mathrm{PG}$ structure.
The LIT MS ${ }^{2}$ spectrum of the $[\mathrm{M}-\mathrm{H}+2 \mathrm{Li}]^{+}$ions at $\mathrm{m} / \mathrm{z} 733$ (Figure $4 \mathrm{~d}$ ) contains a dilithiated diacylglycerol fragment ion at $m / z 579$ and a monolithiated diacylglycerol ion at $m / z 573$, along with the ion pairs at $m / z 477$ $\left(733-\mathrm{C}_{15} \mathrm{H}_{31} \mathrm{CO}_{2} \mathrm{H}\right)$ and $479\left(733-\mathrm{C}_{15} \mathrm{H}_{29} \mathrm{CO}_{2} \mathrm{H}\right)$ from the respective losses of the 16:0 and 16:1-fatty acids, and at $m / z 403(477-74)$ and $405(479-74)$ from further loss of polar head group. The former ion in each pair is more abundant than the latter, suggesting that the ion at $\mathrm{m} / \mathrm{z}$ 733 is consisted of a major 16:0/16:1-PG structure. This assignment is consistent with the presence of the ions at $\mathrm{m} / \mathrm{z} 267$ and 269 representing a dilithiated 16:1-and 16:0-fatty acid cations, respectively, in the $\mathrm{MS}^{3}$ spectrum of the ion at $m / z 579(733 \rightarrow 579$, Figure $4 \mathrm{e})$. The location of the double-bond on the 16:1-fatty acid substituent is unveiled by further dissociation of the ion at $\mathrm{m} / \mathrm{z} 267$ (733 $\rightarrow 579 \rightarrow 267$, Figure 4 f), which gives rise to a $\mathrm{MS}^{4}$ spectrum that contains a prominent ion-pair at $\mathrm{m} / \mathrm{z} 197$ 
and 141, and the distonic ion pairs at $m / z 196$ and 142, along with $\mathrm{m} / \mathrm{z} 155,113$, and 99, indicating that the double-bond is located at $C(9)$. The above results indicate that the ion mainly arises from a $16: 0 / \Delta^{9} 16: 1-\mathrm{PG}$ isomer.

\section{Characterization of Phosphatidylserine from Bovine Brain}

In the positive-ion ESI mass spectrum arising from bovine brain extract, the major dilithiated adduct ions of unsaturated phosphatidylserine were seen at $m / z 802$ and 848 (data not shown). The $\mathrm{MS}^{2}$ spectrum of the [M $\mathrm{H}+2 \mathrm{Li}]^{+}$ions at $m / z 802$ (Figure 5a) is dominated by the ion at $m / z 715$ arising from loss of serine (loss as [serine $-\mathrm{H}_{2} \mathrm{O}$ ]) residue. This ion along with the ion at $\mathrm{m} / \mathrm{z} 605$, arising from loss of the phosphoserine moiety as a dilithium salt indicates that the compound is a phosphatidylserine [12]. Further dissociation of the ion at $m / z 715(802 \rightarrow 715$, Figure $5 b)$ gives the ions at $m / z$ 431 and 433, arising from further losses of 18:0- and 18:1-fatty acid substituents, respectively. The ion at $\mathrm{m} / \mathrm{z}$ 431 is more abundant than the ion at $m / z$ 433, indicating that 18:0- and 18:1-fatty acid substituents are mainly located at $s n-1$ and $s n-2$, respectively [12]. The results lead to assignment of a major 18:0/18:1-PS regioisomer.

The position of the double-bond of the 18:1-fatty acid is unveiled by the product-ion spectra from $\mathrm{MS}^{4}$ on $\mathrm{m} / \mathrm{z}$ $431\left(802 \rightarrow 715 \rightarrow 431\right.$, not shown) and from $\mathrm{MS}^{5}$ on $\mathrm{m} / \mathrm{z}$ $295(802 \rightarrow 715 \rightarrow 431 \rightarrow 295$, not shown), which are identical to those shown in Figure $2 \mathrm{~h}$ and Figure s1c, respectively. These spectra demonstrated that the compound is a $18: 0 / \Delta^{9} 18: 1-$ PS.

Similarly, the $\mathrm{MS}^{2}$ spectrum of the $[\mathrm{M}-\mathrm{H}+2 \mathrm{Li}]^{+}$ ion at $m / z 848$ (Figure 5c), another major ion found in the same extract is dominated by the ion at $\mathrm{m} / \mathrm{z} 761$ (848 [serine $-\mathrm{H}_{2} \mathrm{O}$ ]) along with the ion at $m / z$ 651, arising from loss of the phosphoserine moiety as a dilithium salt. The assignment of the major 18:0/22:6-PS structure seen for the ion at $m / z 848$, again, was based on the findings that the ion at $m / z 477(761-284)$ arising from loss of 18:0-fatty acid is more prominent than the ion at $m / z 433$ (761 - 328), arising from loss of 22:6-fatty acid moiety in the $\mathrm{MS}^{3}$ spectrum of the ion at $m / z 761(848 \rightarrow$ 761, Figure 5d).

Further dissociation of the ion at $m / z 477(848 \rightarrow$ $761 \rightarrow 477$, Figure 5e) leads to the formation of a prominent ion at $\mathrm{m} / \mathrm{z} 341$, which represents a dilithiated ion of 22:6-fatty acid and gives rise to a $\mathrm{MS}^{5}$ spectrum $(848 \rightarrow 761 \rightarrow 477 \rightarrow 341$, Figure 5f) nearly identical to the LIT MS ${ }^{2}$ spectrum of dilithiated $\Delta^{4,7,10,13,16,19}-22: 6$ fatty acid [10]. The $\mathrm{MS}^{4}$ spectrum of the ion of $\mathrm{m} / \mathrm{z} 477$ (Figure 5e) also contains two series ions at $m / z$ 421, 381, 341 (also a dilithiated 22:6 ion), 301, 261, and at $m / z 369$, 329,289 , and 249 arising from the similar fragmentation processes that result in the ion series of $m / z 285,245$, $205,165,125$, and of $m / z 233,193,153$, and 113 , seen in Figure 5f. The results confirm that the ion at $m / z 848$ represents a $18: 0 / \Delta^{4,7,10,13,16,19}-22: 6-P S$.
The ions at $m / z$ 221, 209 and 167 (Figure 5f), are absent in the LIT MS ${ }^{2}$ spectrum of the $[\mathrm{M}-\mathrm{H}+2 \mathrm{Li}]^{+}$ ion of $\Delta^{4,7,10,13,16,19}-22: 6$ standard [10]. This is consistent with the notion that the ion at $m / z 341$ seen in Figure 5e represents a dilithiated ion of 22:6-fatty acid, as well as a terminally conjugated ion, which arises from cleavage of $C(12)-C(13)$ bond with shift of the allylic hydrogen at $\mathrm{C}(9)$ to $\mathrm{C}(13)$. This terminally conjugated ion at $\mathrm{m} / \mathrm{z}$ 341 gives rise to the ion at $m / z 167$ by elimination of the $\Delta^{4,7,9,11} 12: 4-\mathrm{FA}$ as a ketene (route a), and the ion at $m / z 209$ by cleavage of the $\mathrm{C}(3)-\mathrm{C}(4)$ bond with shift of the $\alpha$-hydrogen (route b), along with the ion at $m / z$ 221 by loss of a conjugated 1,3,5,7,9-octapentaene (route c) (Scheme s1, supplementary material).

\section{Conclusions}

The combined structural information from the production spectra from $\mathrm{MS}^{\mathrm{n}}(n=2,3,4,5)$ on the $[\mathrm{M}+\mathrm{Li}]^{+}$, $[\mathrm{M}-\mathrm{H}+2 \mathrm{Li}]^{+}$, or the $[\mathrm{M}-2 \mathrm{H}+3 \mathrm{Li}]^{+}$ion are readily applicable for characterization of all the glycerophospholipids including their plasmalogen and lysophospholipid subclasses. The structure of GPL molecules, including the identity of the fatty acid substituents, the site of unsaturated bond(s) of the fatty acids and their location on the glycerol backbone, as well as the identity of the polar head group can be unveiled in detail. The multiple-stage tandem mass spectrometric approach also adds another dimension for ion separation, resulting in a "purer" tandem mass spectrum for structure identification. For example, the $\mathrm{MS}^{2}$ spectrum of the $[\mathrm{M}-\mathrm{H}+2 \mathrm{Li}]^{+}$ion of $\Delta^{9} 18: 1$-fatty acid standards also contains the unexpected high abundance of the ions at $m / z 277$ and 243 [10] arising from fragmentation of the isobaric background ion of $m / z 295$ from ion source (data not shown). These ions are of low abundance in the $\mathrm{MS}^{4}$ spectrum of $\mathrm{m} / \mathrm{z} 295$ originated from 16:0/18:1-PE (Figure 2c) or from 18:1/0-PA. However, the ions available for detection substantially decline as subsequent ion isolation and resonance excitation in the ion-trap is employed, resulting in loss of sensitivity. Therefore, sustained signal average is required for confident assignment, in particular, of the location of the unsaturated bond(s) of the minute GPL species in mixtures.

\section{Acknowledgments}

The authors acknowledge support for this research by U.S. Public Health Service grants P41-RR-00,954, R37-DK-34,388, P60-DK20,579, and P01-HL-57,278 and P30-DK56341.

\section{References}

1. Pulfer, M.; Murphy, R. C. Electrospray Mass Spectrometry of Phospholipids. Mass Spectrom. Rev. 2003, 22, 332-364.

2. Hsu, F. F.; Turk, J. Electrospray Ionization with Low-Energy Collisionally Activated Dissociation Tandem Mass Spectrometry of Complex Lipids: Structural Characterization and Mechanisms of Fragmentation. In Modern Methods for Lipid Analysis by Liquid Chromatography/Mass Spectrometry; Byrdwell, W. C. Ed.; AOCS Press: Champaign, IL, 2005; p. 61-178. 
3. Moe, M. K.; Anderssen, T.; Strøm, M. B.; Jensen, E. Vicinal Hydroxylation of Unsaturated Fatty Acids for Structural Characterization of Intact Neutral Phospholipids by Negative Electrospray Ionization Tandem Quadrupole Mass Spectrometry. Rapid Commun. Mass Spectrom. 2004, 18, 121-130.

4. Moe, M. K.; Anderssen, T.; Strøm, M. B.; Jensen, E. Total Structure Characterization of Unsaturated Acidic Phospholipids Provided by Vicinal Dihydroxylation of Fatty Acid Double Bonds and Negative Electrospray Ionization Mass Spectrometry. J. Am. Soc. Mass Spectrom. 2005, 16, 46-59.

5. Thomas, M. C.; Mitchell, T. W.; Harman, D. G.; Deeley, J. M.; Nealon, J. R.; Blanksby, S. J. Ozone-Induced Dissociation: Elucidation of Double Bond Position within Mass-Selected Lipid Ions. Anal Chem. 2008, 80, 303-311.

6. Thomas, M. C.; Mitchell, T. W.; Harman, D. G.; Deeley, J. M.; Murphy, R. C.; Blanksby, S. J. Elucidation of Double Bond Position in Unsaturated Lipids by Ozone Electrospray Ionization Mass Spectrometry. Anal Chem. 2007, 79, 5013-22.

7. Thomas, M. C.; Mitchell, T. W.; Blanksby, S. J. Ozonolysis of Phospholipid Double Bonds During Electrospray Ionization: A New Tool for Structure Determination. I. Am. Chem. Soc. 2006, 128, 58-59.

8. Harrison, K. A.; Murphy, R. C. Direct Mass Spectrometric Analysis of Ozonides: Application to Unsaturated Glycerophosphocholine Lipids. Anal. Chem. 1996, 68, 3224-3230.

9. Hsu, F. F.; Turk, J. Distinction Among Isomeric Unsaturated Fatty Acids as Lithiated Adducts by Electrospray Ionization Mass Spectrometry Using Low Energy Collisionally Activated Dissociation on a Triple Stage Quadrupole Instrument. J. Am. Soc. Mass Spectrom. 1999, 10, $600-612$.
10. Hsu, F. F.; Turk, J. Elucidation of the Double bond Position of LongChain Unsaturated Fatty acids by Multiple-Stage Linear Ion-Trap Mass Spectrometry with Electrospray Ionization. J. Am. Soc. Mass Spectrom. 2008, 19, in press.

11. Hsu, F. F.; Turk, J. Characterization of Phosphatidylethanolamine as a Lithiated Adduct by Triple Quadrupole Tandem Mass Spectrometry with Electrospray Ionization. J. Mass Spectrom. 2000, 35, 595-606.

12. Hsu, F. F.; Turk, J. Studies on Phosphatidylserine by Tandem Quadrupole and Multiple Stage Quadrupole Ion-Trap Mass Spectrometry with Electrospray Ionization: Structural Characterization and the Fragmentation Processes. J Am. Soc. Mass Spectrom. 2005, 16, 1510-1522. Erratum in: J. Am. Soc. Mass Spectrom. 2006, 17, 640.

13. Hsu, F. F.; Turk, J. Electrospray Ionization/Tandem Quadrupole Mass Spectrometric Studies on Phosphatidylcholines: The Fragmentation Processes. J. Am. Soc. Mass Spectrom. 2003, 14, 352-363.

14. Hsu, F. F.; Turk, J. Structural Characterization of Triacylglycerols as Lithiated Adducts by Electrospray Ionization Mass Spectrometry Using Low-Energy Collisionally Activated Dissociation on a Triple Stage Quadrupole Instrument. J. Am. Soc. Mass Spectrom. 1999, 10, 587-599.

15. Hsu, F. F.; Turk, J.; Thukkani, A. K.; Messner, M. C.; Wildsmith, K. R.; Ford, D. A. Characterization of Alkylacyl, alk-1-enylacyl, and lyso subclasses of glycerophosphocholine by tandem quadrupole mass spectrometry with electrospray ionization. J. Mass Spectrom. 2003, 38, 752763.

16. Hsu, F. F.; Turk, J.; Zhang, K.; Beverley, S. M. Characterization of Inositol Phosphorylceramides from Leishmania major by Tandem Mass Spectrometry with Electrospray Ionization. J. Am. Soc. Mass Spectrom. 2007, 18, 591-604. 